Original Research Article

\title{
Correlation between glycemic control and dyslipidemia in Type 2 Diabetes Mellitus patient
}

\author{
Neha Yadav ${ }^{1}$, Sujata Singh ${ }^{1 *}$, Smita Gupta ${ }^{2}$, Saurabh Mishra ${ }^{3}$, Krishna Singh ${ }^{1}$
}

\begin{abstract}
${ }^{1}$ Department of Pharmacology, ${ }^{2}$ Department of Medicine, ${ }^{3}$ Department of Community Medicine, Shri Ram Murti Smarak Institute of Medical Sciences, Bareilly, Uttar Pradesh, India
\end{abstract}

Received: 10 April 2019

Accepted: 07 May 2019

*Correspondence to: Dr. Sujata Singh,

Email: sujatasinghdr@rediffmail.com

Copyright: (C) the author(s), publisher and licensee Medip Academy. This is an openaccess article distributed under the terms of the Creative Commons Attribution NonCommercial License, which permits unrestricted noncommercial use, distribution, and reproduction in any medium, provided the original work is properly cited.

\begin{abstract}
Background: India is one of the countries with highest number of diabetes patients. Patients of type 2 diabetes mellitus are usually dyslipidemic. The objective of the research was to study the pattern of dyslipidemia and to study the correlation of glycemic control with dyslipidemia in type 2 diabetes mellitus patients.
\end{abstract}

Methods: A cross sectional observational study was performed on patients of type 2 diabetes mellitus over 6 months period. The study included 200 patients and the variables recorded were demographic profile, FBS, PPBS, HbA1C and lipid profile parameters. The patients were divided into 3 groups according to HbA1C level i.e. Group I (Good glycemic control HbA1C 6-7 gm\%), group II (Fair glycemic control HbA1C 7.1-8.2 gm\%) and group III (poor glycemic control, $\mathrm{HbA} 1 \mathrm{C}>8.2$ gm\%).

Results: The data showed that TG level was maximum in group III and was minimum in group I. Comparison between the group shows a significant difference between all the groups $(\mathrm{P}<0.001)$. A significant positive correlation (Correlation coefficient $0.67, \mathrm{P}<0.001$ ) was also observed between level of TG and HbA1C. Similarly, LDL level was also highest in group III with a significant difference with other two groups $(\mathrm{P}<0.05)$. Also, a positive correlation (Correlation coefficient $0.64, \mathrm{P}<0.05$ ) was observed between LDL and HbA1C. On the other hand, HDL was lowest in group III as compared to groups I and II $(\mathrm{P}<0.001)$ and a negative correlation (Correlation coefficient $-0.716, \mathrm{P}<0.001$ ) was seen between HDL and HbA1C.

Conclusions: Dyslipidemia is less prevalent in diabetics who have better glycemic control.

Keywords: Dyslipidemia, Glycemic control, HbA1C, Type 2 diabetes mellitus

\section{INTRODUCTION}

Diabetes is one of the commonest diseases prevalent in India and all over the world. WHO defines diabetes mellitus as "A metabolic disorder of multiple etiology characterized by chronic hyperglycemia with disturbances of carbohydrate, fat and protein metabolism resulting from defects in the insulin secretion, insulin action, or both". ${ }^{1,2}$ Most people with this condition have Type 2 diabetes. $^{2}$ The chronic hyperglycemia of diabetes is associated with long-term damage, dysfunction and failure of various organs, especially the eyes, kidneys, nerves, heart and blood vessels (microvascular and macrovascular complications). These complications are mainly due to diabetic vasculopathy for which overall temporal burden of hyperglycemia is responsible. ${ }^{3}$ Although the vascular risk associated with diabetes is supposed to be multifactorial but dyslipidemia plays an important role. The characteristic features of diabetic dyslipidemia are a high plasma Triglyceride (TG) concentration, low HighDensity Lipoproteins (HDL) concentration, and increased concentration of Low-Density Lipoproteins (LDL) 
particles. Some studies have also shown that dyslipidemia in diabetic patients is more atherogenic., ${ }^{4,5}$

Glycated hemoglobin (HbA1C) is routinely used as a diagnostic tool for measuring long term glycemic control. Improved glycemic control generally has shown to have favorable effects on lipoprotein levels in diabetes, with a reduction in cholesterol and triglyceride levels through decreased circulating Very Low-Density Lipoprotein (VLDL) and by increased catabolism of LDL through reduced glycation and up-regulation of LDL receptors. ${ }^{6-8}$

Very few studies have evaluated the effect of glycemic control on dyslipidemia particularly in Indian population. With this background the present research was planned to study the pattern of dyslipidemia and the correlation of HbA1C (diagnostic tool for glycemic control) with dyslipidemia in type 2 diabetes mellitus patients.

\section{METHODS}

The present cross-sectional observational study was done over a period of 6 months i.e. from January 2017 to June 2017 in the department of Pharmacology. Before starting the research protocol ethical clearance was taken from the Institutional Ethics Committee.

The subjects for the study were recruited from the Outpatients Department of General Medicine at SRMS IMS Bareilly, Uttar Pradesh, India a tertiary care, teaching and super-specialty hospital.

\section{Inclusion criteria}

- Patients (either sex) suffering from Type 2 DM,

- Patients on anti-diabetic medication for more than 6 months and less than 5 years.

\section{Exclusion criteria}

- Patients with Type I DM,

- Patients with any malignancy,

- Pregnant and lactating females,

- Indoor patients,

- Patients on Insulin.

\section{Sample size}

Sample size was calculated as under.

- According to the Indian Diabetic Fraderation Diabetes Atlas 2015 Updates, 7th edition.

Prevalence of diabetes- $8.5 \%$

Standard normal variation (at 5\% absolute error) is 1.96 .

Sample Size $=\mathrm{Z} 1-\mathrm{a} / 22 \mathrm{p}(1-\mathrm{p}) / \mathrm{d}^{2}$
Where, $\mathrm{Z} 1-\mathrm{a} / 22=$ is standard normal variants (at 5\% type 1 error $(\mathrm{P}<0.05)$ it is $1.96, \mathrm{p}=$ Expected proportion in population based on previous studies, $\mathrm{d}=$ Absolute error or precision $(5 \%)$

Sample size $=184($ approx. 200$)$

A total of 200 patients (as per calculated sample size) fulfilling the inclusion criteria were recruited to the study protocol. Informed consent was obtained from all the patients before including them in the study.

Glycemic level was assessed by measuring Fasting Blood Sugar (FBS), Post prandial Blood Sugar (PPBS) and Glycated haemoglobin (HbA1C).

- Blood samples for FBS were collected after minimum 8 hours of overnight fasting,

- Blood samples for PPBS were collected 2 hours after the breakfast,

- HbA1C levels were estimated from the sample for PPBS.

On the basis of HbA1C the enrolled patients were categorized into 3 groups: Group I (Good glycemic control HbA1C 6-7 gm\%), group II (Fair glycemic control HbA1C 7.1-8.2 $\mathrm{gm} \%$ ) and group III (Poor glycemic control, HbA1C > 8.2 gm\%). ${ }^{9}$

Lipid profile

- Following lipoprotein level was determined in fasting venous blood samples viz.

- Total cholesterol,

- Serum TG levels,

- Serum HDL levels,

- Serum LDL levels,

- $\quad$ All these parameters were analyzed by Enzymatic Assay using Minray Medical Kit (BS 380), China stored at $2-8^{\circ} \mathrm{C}$.

The data collected was analyzed by Chi- square, Student'st-test and Correlation test using SPSS version 20.0 statistical package.

\section{RESULTS}

The enrolled patients were divided into 3 groups as mentioned above. Group I included $36.5 \%$ patients, group II included $34.5 \%$ patients whereas group III includes $29 \%$ patients (Table 1).

On comparison between different groups it was observed that group III is having highest levels of mean FBS as well as mean PPBS (Table 1).

Out of total patients enrolled $48 \%$ were male and $52 \%$ were female. There was no significant difference in male:female ratio between different groups (Figure 1). 
Table 1: Group wise distribution of blood sugar levels.

\begin{tabular}{|lllll|}
\hline Groups & $\begin{array}{l}\text { HbA1C } \\
(\mathbf{g m} \%)\end{array}$ & $\begin{array}{l}\text { No. of } \\
\text { patients }\end{array}$ & $\begin{array}{l}\text { Mean } \\
\text { FBS } \pm \text { SD } \\
(\mathbf{m g} / \mathbf{d l})\end{array}$ & $\begin{array}{l}\text { Mean } \\
\text { PPBS } \pm \text { SD } \\
(\mathbf{m g} / \mathbf{d l})\end{array}$ \\
\hline Group I & $6-7$ & 73 & 107.20 & 181.89 \\
\hline Group II & $7.1-8.2$ & 69 & 137.63 & 224.69 \\
\hline Group III $>8.2$ & 58 & 241.10 & 355.94 \\
\hline
\end{tabular}

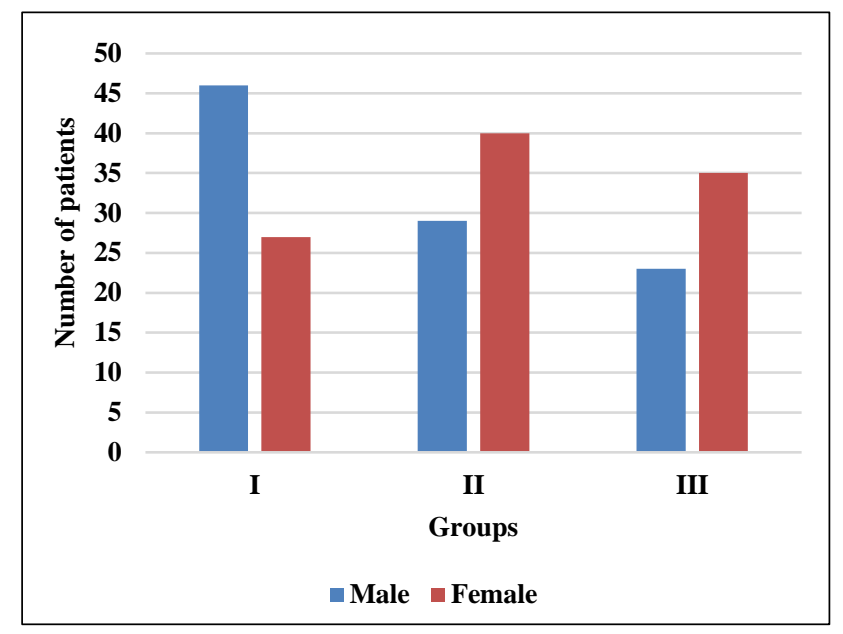

Figure 1: Group wise distribution of gender.

\section{Demographic profile}

Demographic profile of the enrolled patients shows that working status, gender, and family history shows significant difference in different groups ( $\mathrm{P}$ value $<0.05)$ indicating association of these factors with the level of $\mathrm{HbA1C}$, i.e. Glycated hemoglobin was more when family history was positive, in working patients and in female patients. Whereas, there was no significant difference in different groups for dietary habit and age (Table 2).

There was significant difference in BMI between groups II and III $(25.47 \pm 5.69$ vs $27.30 \pm 4.28, \mathrm{P}$ value $<0.05)$ and between groups I and III $(26.17 \pm 5.17$ vs $27.30 \pm 4.28, \mathrm{P}$ value $<0.05)$ whereas no significant difference was seen between groups I and II $(26.17 \pm 5.17$ vs $25.47 \pm 5.69, \mathrm{P}$ value $>0.05$ ) (Table 2).

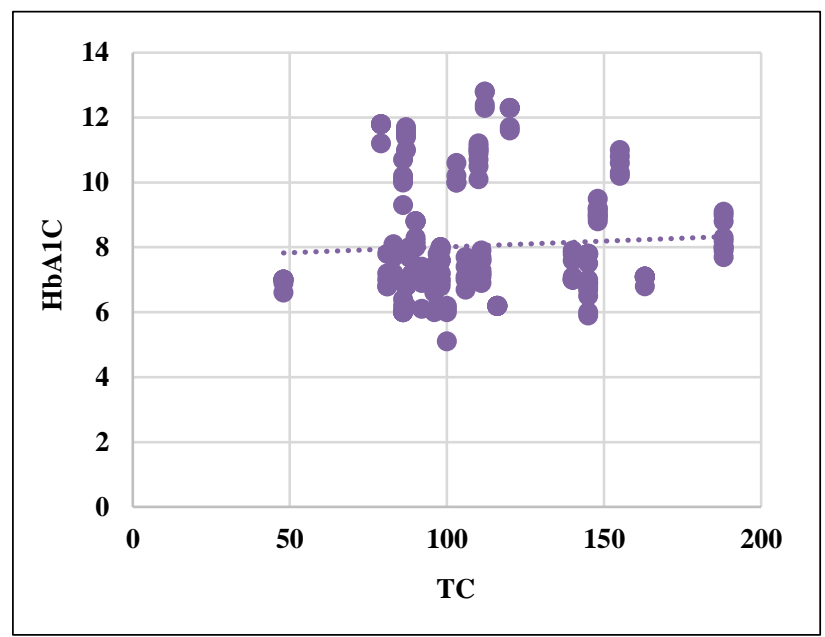

Figure 2: Correlation between $\mathrm{HbA1C}$ and TC.

Table 2: Demographic profile.

\begin{tabular}{|lllllllll|}
\hline Groups & $\begin{array}{l}\text { No. of } \\
\text { pts }\end{array}$ & $\begin{array}{l}\text { Mean Age } \pm \\
\text { SD (yrs.) }\end{array}$ & $\begin{array}{l}\text { Mean BMI } \\
\pm \text { SD }\end{array}$ & $\begin{array}{l}\text { Working: } \\
\text { Non-working }\end{array}$ & $\begin{array}{l}\text { Vegetarian: } \\
\text { Non-vegetarian }\end{array}$ & $\begin{array}{l}\text { Male } \\
\text { Female }\end{array}$ & $\begin{array}{l}\text { Positive } \\
\text { family } \\
\text { history }\end{array}$ \\
\hline Group I & 73 & $45.92 \pm 8.6$ & $26.17 \pm 5.17$ & $53: 20$ & $37: 36$ & 46 & 27 & $39.7 \%$ \\
\hline Group II & 69 & $46.5 \pm 8$ & $25.47 \pm 5.69 * \#$ & $39: 30 \#$ & $45: 24$ & 29 & 40 & $47 \% *$ \\
\hline Group III & 58 & $44.13 \pm 8.9$ & $27.30 \pm 4.28 \#$ & $26: 32 \# \$$ & $24: 34$ & 23 & 35 & $43 \% \$$ \\
\hline
\end{tabular}

*P value $<0.05$ (Group I vs Group II), \# P value <0.05 (Group II vs Group III), \$P value <0.05 (Group I vs Group III).

Table 3: Group wise distribution of different parameters of lipid profile.

\begin{tabular}{|lllllll|}
\hline Groups & $\begin{array}{l}\text { HbA1C } \\
(\mathbf{G m} \%)\end{array}$ & $\begin{array}{l}\text { No. of } \\
\text { pts }\end{array}$ & $\begin{array}{l}\text { Mean TG } \pm \text { SD } \\
(\mathbf{m g} / \mathbf{d l})\end{array}$ & $\begin{array}{l}\text { Mean LDL- } \\
\mathbf{C} \pm \text { SD }(\mathbf{m g} / \mathbf{d l})\end{array}$ & $\begin{array}{l}\text { Mean HDL-C } \pm \text { SD } \\
(\mathbf{m g} / \mathbf{d l})\end{array}$ & $\begin{array}{l}\text { Mean TC } \pm \text { SD } \\
(\mathbf{m g} / \mathbf{d l})\end{array}$ \\
\hline Group I & $6-7$ & 73 & $148.46 \pm 94.7$ & $99.65 \pm 27.59$ & $50.80 \pm 7.3$ & $163.65 \pm 44.27$ \\
\hline Group II & $7.1-8.2$ & 69 & $210.23 \pm 77.59 * \#$ & $116.33 \pm 33.24 * \#$ & $43.75 \pm 9.50 * \#$ & $175.13 \pm 54.49$ \\
\hline Group III & $>8.2$ & 58 & $347.63 \pm 165.6 \# \$$ & $117.56 \pm 31.5 \# \$$ & $29.81 \pm 7.43 \# \$$ & $181.96 \pm 38.77$ \\
\hline
\end{tabular}

*P value $<0.05$ (Group I vs Group II), \# P value <0.05 (Group II vs Group III), \$P value <0.05 (Group I vs Group III).

\section{Lipid profile}

NCEP Guidelines were used for definition of dyslipidemia.

\section{Total Cholesterol (TC)}

Observations from the collected data shows hypercholesterolaemia (defined as TC >200 mg/dl) in $24.5 \%$ of patients and maximum belonged to group III. 
On comparison of TC level between three groups, it was observed that it was maximum in group III and least in group I although the difference was not statistically significant (Table 3). Although a positive correlation was observed between $\mathrm{TC}$ and $\mathrm{HbA1C}$, but it was not significant (Correlation coefficient: 0.029, P value: 0.68) (Figure 2).

\section{Triglyceride (TG)}

The data shows $60.5 \%$ patients had hypertriglyceridemia (Defined as TG $>150 \mathrm{mg} / \mathrm{dl}$ ). TG level was maximum in group III and was minimum in group I. Comparison between the group shows a significant difference between all the groups (P value <0.001) (Table 3). A significant positive correlation (Correlation coefficient: 0.67 , $\mathrm{P}$ value: $<0.001$ ) was also seen between TG and HbA1C (Figure 3).

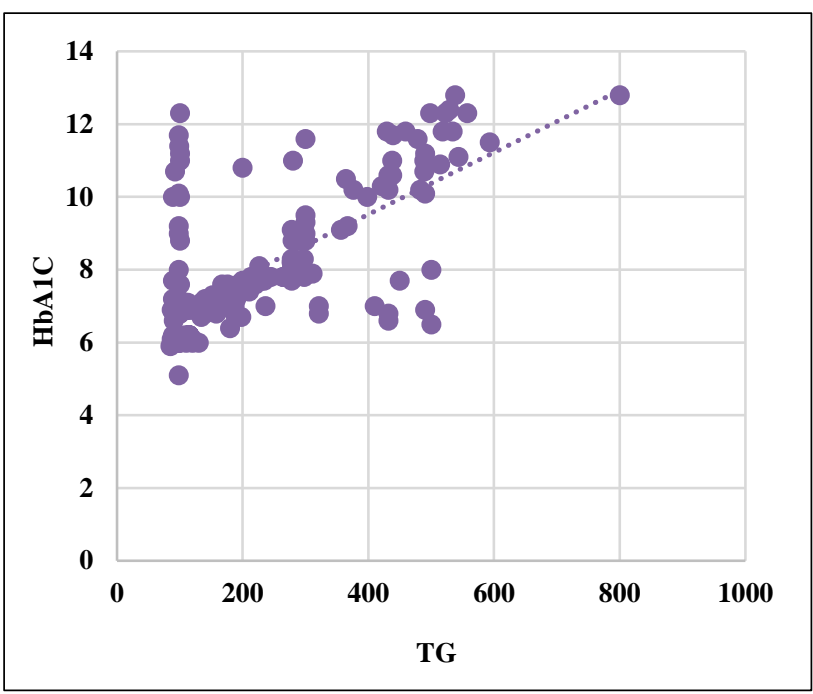

Figure 3: Correlation between HbA1C and TG.

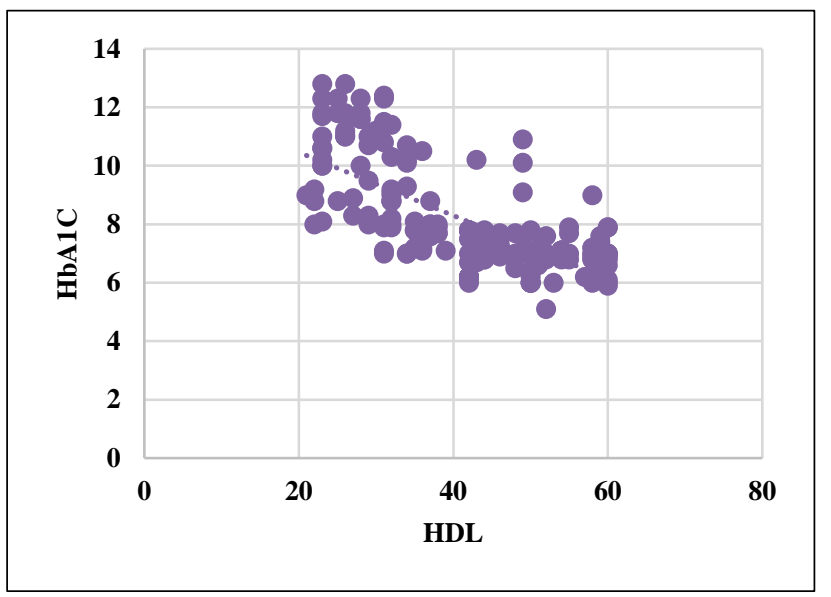

Figure 4: Correlation between HbA1C and HDL.

\section{High density lipoproteins (HDL)}

On analysing the data $41 \%$ patients had hypo high density lipoproteinemia (Defined as HDL $<40 \mathrm{mg} / \mathrm{dl}$ in males and
$<50 \mathrm{mg} / \mathrm{dl}$ in females). In contrast to TG, HDL level was maximum in group I and was minimum in group III. Comparison between the group shows a significant difference between all the groups ( $\mathrm{P}$ value <0.001) (Table 3). A significant negative correlation (Correlation coefficient: -0.716 , P value: $<0.001)$ was seen between HDL and HbA1C (Figure 4).

\section{Low Density Lipoproteins (LDL)}

The study shows $27 \%$ patients had hyper low density lipoproteinemia (Defined as LDL $>130 \mathrm{mg} / \mathrm{dl}$ ). None of the patients in group I had hyper low density lipoproteinemia. Similar to TG, LDL level was maximum in group III and was minimum in group I. Comparison between the groups shows a significant difference between all the groups ( $\mathrm{P}$ value $<0.05$ ) (Table 3 ). In addition a significant positive correlation (Correlation coefficient: 0.64 , P value: <0.05) was seen between LDL and HbA1C (Figure 5).

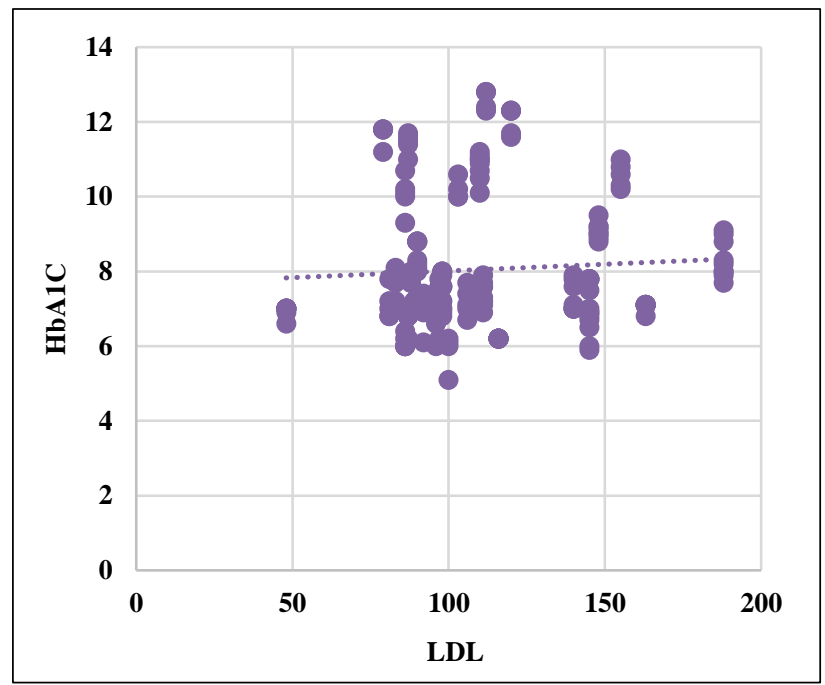

Figure 5: Correlation between HbA1C and LDL.

\section{DISCUSSION}

The incidence of Type $2 \mathrm{DM}$ is increasing all over the world and about $75 \%$ are living in developing countries. ${ }^{10}$ Many of the studies done in different regions of the world have observed high level of dyslipidemia among Type 2 DM patients. Further, DM is also a common secondary cause of dyslipidemia particularly, if glycemic control is poor. ${ }^{11}$ So, the present study was done to see the pattern of dyslipidemia and to study the correlation between lipid profile and glycemic control in Type 2 DM patients.

In this study, the prevalence of diabetes was found to be more common among female population with a male: female ratio of $1: 1.4$. This is in accordance with other studies conducted by John et al, and Ramesh R et al, who have also reported a high proportion of diabetes in females. ${ }^{12,13}$ While few studies have also shown opposite result where male predominance was seen. ${ }^{14,15}$ 
Among the study participants $59.5 \%$ patients were working and $40.5 \%$ patients were non-working. This indicates the prevalence of Type $2 \mathrm{DM}$ is more in working population. This may be due to high level of stress which may contribute to the development of diabetes. Familial association with diabetes mellitus Type 2 was seen in $43.5 \%$ of the patients. Similar results have been reported in other studies. ${ }^{16,17}$ Authors observed that BMI was significantly more in group III as compared to groups I and II indicating increased $\mathrm{HbA} 1 \mathrm{C}$ levels in obese population. Studies done in past shows similar type of results and have also reported a positive correlation between BMI and HbA1C. ${ }^{18,19}$

The study showed hypercholesterolaemia in $24.5 \%$ of patients, hypertriglyceridemia in $60.5 \%$ patients, hypo high density lipoproteinemia in $41 \%$ patients and hyper low density lipoproteinemia 27\% patients (Dyslipidemia levels defined as per NCEP guidelines). ${ }^{20}$ The dyslipidemia observed in present study is similar to the observations of other studies done in Indian population and also in other countries. $^{6-8}$ Most of the studies have shown hypercholesterolaemia, hypertriglyceridemia, hypo high density lipoproteinemia, hyper low density lipoproteinemia. Although the degree of dyslipidemia is slightly less in the present study. This difference could be because in this study maximum number of patients belonged to group I i.e. good glycemic control. Moreover, the enrolled patients were suffering from diabetes for not more than 5 years. This also suggests that improved glycemic control or decrease in $\mathrm{HbA} 1 \mathrm{C}$ reduces the level of dyslipidemia. In other words, improved glycemic control has favourable effect on lipid profile. Other studies done in past shows a similar type of result. Schwartz SL et al, in his study showed that improving glycemic control can reduce LDL-C by 10 to $15 \%$ and also produce a favourable change in the composition of LDL-C particles. ${ }^{8}$ Some other studies have also shown a similar trend where glycemic control favorably affects lipoprotein levels in diabetes.

The observations show a significant positive correlation of HbA1C with LDL-C and TG levels. The data also shows significant negative correlation with HDL-C. This is in accordance with other studies done by Taliyan $\mathrm{S}$ et al, and Khan et al. They have shown that there is a direct correlation between $\mathrm{HbA} 1 \mathrm{C}$ and FBS with TG and LDL and inverse correlation with HDL. ${ }^{21,22}$ Wexelar et al, has shown dyslipidemia incidence more in type 2 DM patients. ${ }^{23}$ Low levels of TG and LDL can reduce the risk of CVD and reduces the mortality rate of diabetic patients. ${ }^{24}$ There are evidences suggesting that dyslipidemia is secondary to insulin resistance or factors closely related to insulin resistance, such as adiposity. This interrelationship could be because of increased free fatty acid flux, increased proinflammatory adipokines and cytokines secondary to insulin resistance commonly seen in Type 2 DM. ${ }^{25,26}$ The increase of triglyceride (TG) levels in diabetic patients is due to reduction of lipoprotein lipase (LPL) activity. ${ }^{27}$ On the other hand, some studies also hypothesize that dyslipidemia could be important contributing factor in the pathogenesis of type 2 DM. $^{28}$

The significant association of $\mathrm{HbA} 1 \mathrm{C}$ with various lipid parameters as observed in the present study signifies the role of improving glycemic control in diabetes management.

As elevated $\mathrm{HbA} 1 \mathrm{C}$ and dyslipidemia are independent risk factors of CVD, diabetic patients with elevated $\mathrm{HbA} 1 \mathrm{C}$ and dyslipidemia can be considered as a very high-risk group for CVD. Improving glycemic control can substantially reduce the risk of cardiovascular events in diabetics. ${ }^{29} \mathrm{It}$ has been reported that reducing the $\mathrm{HbA} 1 \mathrm{C}$ level by $0.2 \%$ could lower the mortality by $10 \% .30$ Thus, the results of the present study signifies the importance of glycemic control in order to limit dyslipidemia and risk for cardiovascular diseases in type 2 diabetics.

\section{CONCLUSION}

In the present study, authors observed a significant correlation between $\mathrm{HBA} 1 \mathrm{C}$ and different lipid parameters indicating a lesser prevalence of dyslipidemia when HBA1C is within normal limits. Hence, this suggests that improved glycemic control can decrease the incidence of dyslipidemia in diabetic patients which can also decrease cardiovascular complications associated with diabetes associated with diabetes.

The patients for the study were requited from a restricted area which may not represent the entire population. In addition, the patients were suffering from diabetes for not more than 5 years so the complications/ dyslipidemia might be less in this population.

\section{ACKNOWLEDGEMENTS}

Authors would like to thank patients for their support during study.

Funding: No funding sources Conflict of interest: None declared

Ethical approval: The study was approved by the Institutional Ethics Committee

\section{REFERENCES}

1. Maitra A, Abbas AK. Endocrine system. In: Kumar V, Fausto N, Abbas AK, eds. Robbins and Cotran Pathologic Basis of Disease. 7th ed. Philadelphia, Saunders; 2005:1156-226.

2. Dabelea D, Mayer-Davis EJ, Saydah S, Imperatore G, Linder B, Divers J, et al. Prevalence of type 1 and type 2 diabetes among children and adolescents from 2001 to 2009. JAMA. 2014;311:1778-86.

3. Rizvi A, Sanders MB. Assessment and monitoring of glycemic control in primary diabetes care: monitoring techniques, record keeping, meter downloads, tests of 
average glycemia, and point of- care evaluation. J Am Acad Nurse Pract. 2006;18:11-21.

4. Krauss RM. Lipids and lipoproteins in patients with type 2 diabetes. Diab Care. 2004;27:1496-504.

5. Haffner SM. American Diabetes Association Management of dyslipidemia in adults with diabetes. Diab Care. 2003;26(1):s83-6.

6. Daya R, Bayatand Z, Raal FJ. Prevalence and pattern of dyslipidaemia in type 2 diabetes mellitus patients at a tertiary care hospital. J Endocrinol Metab Diab South Africa. 2017;22:3:31-5.

7. Mandal M, Kumari R, Mukherjee A. Prevalence of dyslipidemia in patients with type 2 diabetes mellitus: a hospital based study in Kishanganj, India. Int J Res Med Sci. 2015;3:3691-7.

8. Schwartz SL. Diabetes and dyslipidaemia. Diab Obes Metab. 2006;8(4):355-64.

9. Mahmood K, Aamir AH. Glycemic control status in patients with type-2 diabetes. J Coll Physicians Surg Pak. 2005;15(6):323-5.

10. Diabetes Mellitus: Complications. In: DL Kasper, AS Fauci, DL Longo, SL Hauser, JL Jameson, J Loscalzo, eds. Harrison's Principles of Internal Medicine. New York: McGraw-Hill Education; 2015:2399.

11. Supriya, Mohanty S, Pinnelli VBK. Role of glycated hemoglobin (HBA1c) as a dual marker to predict glycemic status and dyslipidemia in Type 2 diabetes mellitus. Int J Res Med Sci. 2016;4:4524-9.

12. John LJ, Arifulla M, Sreedharan J, Muttappallymyalil J, Das R, John J, et al. Age and gender based utilization pattern of antidiabetic drugs in Ajman, UAE. Malaysian J Pharmaceut Sci. 2012;10(1):79-85.

13. Ramesh R, Kumar SV, Gopinath S, Gavaskar B, Gandhiji G. Diabetic knowledge of rural community and drug utilization pattern in a tertiary care hospital. Int J Pharm Life Sci. 2011;2(1):531-5.

14. Boccuzzi SJ, Wogen J, Fox J. Utilization of oral hypoglycemic agents in a drug-insured U.S. Population. Diab Care. 2004;24:1411-5.

15. Yurgin N, Secnik K, Lage MJ. Antidiabetic prescriptions and glycemic control in German patients with type 2 diabetes mellitus: a retrospective database study. Clin Ther. 2007;29:316-25.

16. Mandal S. Drug utilization study in patients with type 2 diabetes mellitus attending diabetes clinic of a tertiary care hospital in rural Bengal. Int J Basic Clin Pharmacol. 2016;5(4):1647-54.

17. Sharma A, Sharma P, Gaur A, Chhabra M, Kaur R. A cross-sectional study on diabetes mellitus type-2 at a tertiary care hospital. Adv Res Gastro Entero Hepatol; 2017; 8(1):1-6.

18. Bala M, Meenakshi, KM, Gupta A. Correlation of HbA1C levels with body mass index in newly diagnosed polycystic ovary syndrome. EJIFCC. 2017;28(3):196-204.

19. Babikr WG, Alshahrani ASA, Hamid HGM, Ahmed, Abdelraheem HMK, Shalayel MHF. The correlation of $\mathrm{HbA} 1 \mathrm{c}$ with body mass index and HDL-cholesterol in type 2 diabetic patients. Biomedical Res. 2016;27(4):1280-3.

20. Expert Panel on Detection E. Executive summary of the third report of the National Cholesterol Education Program (NCEP) expert panel on detection, evaluation, and treatment of high blood cholesterol in adults (Adult Treatment Panel III). JAMA. 2001;285(19):2486.

21. Taliyan S, Nagtilak S, Parashar P, Rastogi A. Correlation between Glycated hemoglobin and Lipid profile in Type 2 Diabetic population of district Meerut, U.P. Int J Biomed Adv Res. 2016;7(11):5346.

22. Khan HA, Sobki SH, Khan SA. Association between glycaemic control and serum lipid profile in type 2 diabetic patients: HbA1c predicts dyslipidemia. Clin Exp Med. 2007;7(1):24-9.

23. Wexler DJ, Grant RW, Meigs JB, Nathan DM, Cagliero E. Sex disparities in treatment of cardio risk factors in patient with type 2 diabetes. Diab Care. 2005;28(3):514-20.

24. Faghihimani Z, Mirmiran P, Sohrab G, Iraj B, Faghihimani E. Effects of pomegranate seed oil on metabolic state of patients with type 2 diabetes mellitus. Int J Prev Med. 2016;7:124.

25. Chehade JM, Gladysz M, Mooradian AD. Dyslipidemia in type 2 diabetes: Prevalence, pathophysiology, and management. Drugs. 2013;73:327-39.

26. Nikkilä EA, Taskinen MR. Lipoprotein lipase of adipose tissue and skeletal muscle in human obesity: response to glucose and to semistarvation. Metabolism. 1981;30(8):810-7.

27. Kruit JK, Brunham LR, Verchere CB, Hayden MR. HDL and LDL cholesterol significantly influence beta-cell function in type 2 diabetes mellitus. Curr Opin Lipidol. 2010;21:178-85.

28. Pétremand J, Puyal J, Chatton JY, Duprez J, Allagnat F, Frias M, et al. HDLs protect pancreatic $\beta$-cells against ER stress by restoring protein folding and trafficking. Diab. 2012;61:1100-11.

29. Ray KK, Seshasai SR, Wijesuriya S. Effect of intensive control of glucose on cardiovascular outcomes and death in patients with diabetes mellitus: a meta-analysis of randomized controlled trials. Lancet. 2009;373:1765-72.

30. Khaw KT. Glycated haemoglobin, diabetes, and mortality in men in Norfolk cohort of European prospective investigation of cancer and nutrition. Brit Med J. 2001;332:15-8.

Cite this article as: Yadav N, Singh S, Gupta S, Mishra S, Singh K. Correlation between glycemic control and dyslipidemia in Type 2 Diabetes Mellitus patient. Int J Basic Clin Pharmacol 2019;8:1387-92. 